\title{
A new method for endoscopic variceal band ligation in Zenker's diverticulum
}

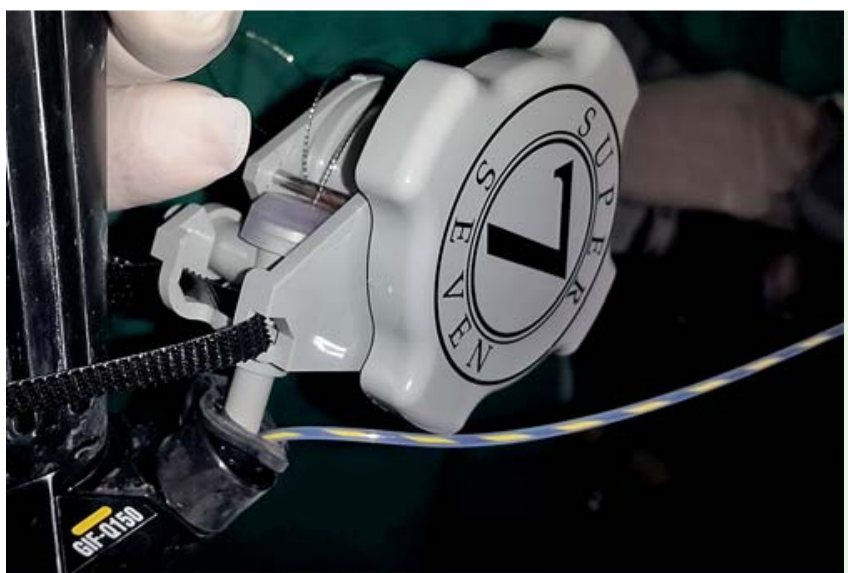

Fig. 1 View of the loaded catheter and the handle of the ligation device.

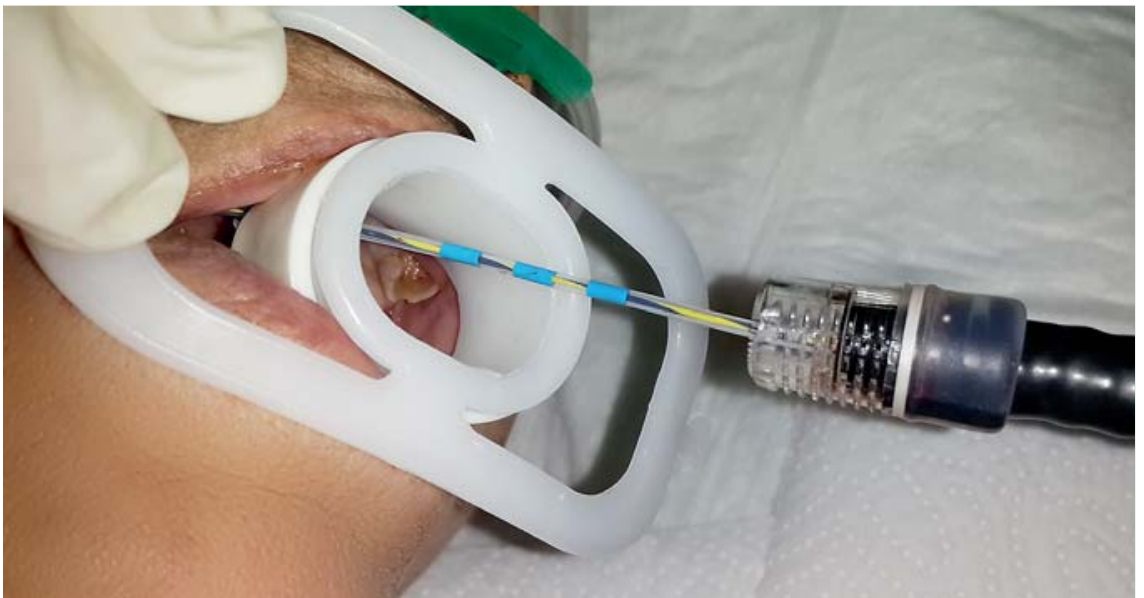

Fig. 2 View of the guidewire, catheter, and the tip of the endoscope with ligation device including bands.

A 62-year-old man was admitted with hematemesis. He had been diagnosed to have hepatitis B-related cirrhosis 4 months earlier, and had not undergone esophagogastroduodenoscopy (EGD) previously. He had no history of dysphagia. During intubation with an endoscope (GIF Q-150, Olympus, Japan), resistance was encountered at the upper esophageal sphincter, and a diverticulum was noted at this level. Although very difficult, the endoscope was passed gently into the esophagus. EGD was performed and esophageal varices with red spots were diagnosed. Endoscopic variceal ligation (EVL) was decided; however we considered that repeated esophageal intubation would be impossible with an affixed band ligation set. Thus, a guidewire (0.035 inch; Boston-Scientific, Marl- borough, MA, United States) was inserted into the stomach via the working channel under endoscopic vision, and the endoscope was withdrawn over the guidewire. An endoscopic band ligator device (Speedband Superview Super 7 Multiple Band Ligator, Boston-Scientific) was fixed to the endoscope. Following that, the endoscope was loaded with a catheter (standard type catheter, Boston-Scientific) beside the handle of the multiple band ligator ( Fig. 1). Thereafter, the guidewire was inserted into the leading end of the catheter and pushed until it passed out from the working channel of the endoscope. The catheter was first advanced to the stomach. The endoscope was then pushed forward over the catheter into the distal esophagus ( $\bullet$ Fig. 2 ). After complete withdrawal of both cathe- ter and guidewire, EVL was performed successfully. The second EVL session was carried out using the same method 4 weeks later.

Esophageal intubation may be difficult in patients with Zenker's diverticulum. Several methods have been reported to intubate the esophagus using an overtube [1], a hydrophilic guidewire [2], or a catheter [3]; however no data exist on the EVL procedure in Zenker's diverticulum. Affixation of an endoscopic band ligator device will make esophageal intubation more difficult and dangerous. On the other hand, the present case shows that if the diagnostic EGD is able to intubate the esophagus, with the guidance of a guidewire and catheter, the EVL procedure is safe and effective in patients with Zenker's diverticulum.

Endoscopy_UCTN_Code_TTT_1AO_2AD

Competing interests: None

\section{Fatih Tekin, Ilker Turan, Omer Ozutemiz}

Ege University Medical School, Department of Gastroenterology, Izmir, Turkey

\section{References}

1 Dickey W, Porter KG. Duodenoscope intubation of the esophagus in the presence of pharyngeal pouch made possible by an overtube. Endoscopy 1995; 27: 272-273

2 Malik A, Chitnavis V, Epstein A. Use of a hydrophilic wire for esophageal intubation in Zenker's diverticulum. Gastrointest Endosc 1994; 40: 523- 524

3 Tsang TK, Buto SK. Catheter guided endoscopic intubation: a new technique for intubating a difficult esophagus. Gastrointest Endosc 1992; 38: 49-51

\section{Bibliography}

Dol http://dx.doi.org/

10.1055/s-0034-1391127

Endoscopy 2015; 47: E38

(c) Georg Thieme Verlag KC

Stuttgart · New York

ISSN 0013-726X

\section{Corresponding author}

\section{Fatih Tekin, MD}

Ege Universitesi Tip Fakultesi

Gastroenteroloji Bilim Dali

Bornova 35100

Izmir

Turkey

Fax: +90-232-3427764

drtekinfatih@gmail.com 